\title{
Potabilidade da água de poços artesianos: diagnóstico de amostras dos municípios do Rio Grande do Sul
}

\author{
Water potability of artisian wells: diagnosis of sample from the counties of Rio Grande do Sul
}

\author{
Sandra Cadore Peixoto' \\ Carolina Denardi Merlugo" \\ Anderson Maciel"II \\ Tiago Barboza Solneriv
}

\section{Resumo}

A água potável é toda água própria para consumo. Deve ter certa quantidade de sais minerais dissolvido, estar livre de materiais tóxicos e micro-organismos. É considerada um recurso indispensável ao homem. Um dos principais problemas para o uso da água está relacionado à sua contaminação, ou seja, este recurso vem sendo poluído de tal maneira que já não se pode consumi-lo em seu estado natural. Contudo, apesar de todos os esforços para armazenar e diminuir seu consumo, está se tornando um bem escasso e sua qualidade se deteriora cada vez mais rápido. Dessa forma, as águas subterrâneas vêm se constituindo como uma importante alternativa para abastecimento hídrico de comunidades. Considerando a relevância deste tema, este estudo busca fazer um diagnóstico da qualidade da água de poços artesianos da Região Central do Estado do Rio Grande do Sul, a fim de comprovar a potabilidade. Para estas determinações os procedimentos experimentais realizados foram: determinação do valor de $\mathrm{pH}$; turbidez; temperatura; sólidos totais dissolvidos; cor; dureza e concentração residual de ferro. A avaliação dos resultados obtidos neste estudo foi baseada nos padrões de potabilidade estabelecidos na Portaria № 2.914 , de 12 de dezembro de 2011, do Ministério da Saúde, que dispõe os procedimentos de controle e vigilância da qualidade da água para consumo humano e seu padrão de potabilidade.

Palavras-chave: Água potável; Análise; Parâmetros de qualidade

\section{Abstract}

Drinking water is all water for consumption. It must have certain amount of dissolved minerals, be free of toxic materials and micro-organisms. It is considered an indispensable resource for man. One of the main problems for the use of water is related to its contamination, that is, this resource has been polluted in such a way that it can no longer consume it in its natural state. However, despite all the efforts to store and reduce its consumption, it is becoming scarce and its quality deteriorates faster and faster. In this way, groundwater has become an important alternative for water supply to communities. Considering the relevance of this theme, this study seeks to make a diagnosis of the water quality of artesian wells of the Central Region of the State of Rio Grande do Sul, in order to prove the potability. For these determinations the experimental procedures were: determination of the $\mathrm{pH}$ value; turbidity; temperature; total solids dissolved; color; hardness and residual iron concentration. The evaluation of the results obtained in this study was based on the standards of potability established in Ordinance No. 2,914, of December 12, 2011, of the Ministry of Health, which establishes the procedures for control and surveillance of water quality for human consumption and its standard of potability.

Keywords: Potable water; Analyze; Quality parameters

\footnotetext{
Universidade Franciscana, Santa Maria, RS, Brasil. e-mail: sandracadore@unifra.br

' Universidade Franciscana, Santa Maria, RS, Brasil. e-mail: carolinamerlugo@gmail.com

II' Universidade Franciscana, Santa Maria, RS, Brasil.e-mail: anderson@unifra.br

Iv Universidade Franciscana, Santa Maria, RS, Brasil.e-mail: tiagosolner@gmail.com
} 


\section{Introdução}

O poço artesiano é um grande buraco feito no solo que capta água ao atingir um lençol aquífero, constituindo uma obra de engenharia geológica de acesso à água subterrânea para sua captação. Realiza seu trabalho através da pressão feita pela corrente d'água, no qual uma extremidade com diâmetro pequeno e grande profundidade é perfurada, superior a 40 metros, em que a água jorra por si só, porque sua própria pressão basta para levá-la à superfície. Porém, em alguns casos torna-se necessário a colocação da moto bomba para que a água seja levada até o reservatório, pois a pressão na qual ela sai na superfície do poço, não é suficiente para levá-la até o compartimento (HIRATA, 2002).

A água é o mais importante recurso natural do mundo e sem ela a vida não poderia existir. Contudo, apesar de todos os esforços para armazenar e diminuir seu consumo, está se tornando um bem escasso e sua qualidade se deteriora cada vez mais rápido. Dessa forma, as águas subterrâneas vêm se constituindo como uma alternativa para abastecimento de comunidades rurais e urbanas.

A qualidade da água para o consumo humano, que atenda aos padrões de potabilidade, é questão relevante para a saúde pública. No Brasil, a Norma de Qualidade da Água para Consumo Humano, definida na Portaria № 518, de 25 de março de 2004, do Ministério da Saúde, estabelece os valores máximos permitidos (VMP) para as características bacteriológicas, organolépticas, físicas e químicas para uma água potável (BRASIL, 2004).

Diante do exposto, este estudo visa diagnosticar a qualidade da água de poços artesianos da Região Central do Estado do Rio Grande do Sul, a fim de comprovar a potabilidade perante aos parâmetros de potabilidade estabelecidos na Portaria № 2.914, de 12 de dezembro de 2011, do Ministério da Saúde. Para isto os procedimentos experimentais realizados foram: determinação do valor de $\mathrm{pH}$; turbidez; temperatura; sólidos totais dissolvidos; cor; dureza e concentração residual de ferro.

\section{Revisão bibliográfica}

\section{A água}

A água é uma substância que pode ser encontrada, naturalmente, em todos os três estados físicos da matéria: sólido (gelo), líquido (água líquida) e gasoso (vapor de água). A densidade da água varia com a temperatura, atingindo o valor máximo para a temperatura próxima a $4{ }^{\circ} \mathrm{C}$. Outra propriedade da água que vale ressaltar é que a forma líquida apresenta uma densidade maior que a forma sólida (GRASSI, 2001).

A presença de gases dissolvidos na água, como oxigênio e o dióxido de carbono, permite a ocorrência da fotossíntese e da respiração aeróbica nesse meio. A solubilidade de um gás na água depende de sua composição, aumentando com a pressão parcial do gás no meio adjacente e diminuindo com a temperatura e com a concentração de substâncias dissolvidas. Em razão da maior concentração de sais dissolvidos, a água do mar apresenta menor concentração de saturação de gases dissolvidos em comparação com a água doce para as mesmas condições de temperatura. A presença de alguns sais dissolvidos na água é fundamental para a constituição das cadeias alimentares no meio aquático, pois eles servem como nutrientes para os organismos autótrofos. Em geral, os sais de fósforo ou de nitrogênio são fatores limitantes para o crescimento desses organismos no ambiente aquático, de modo que um aumento excessivo na concentração desses sais pode gerar uma proliferação exagerada de algas, ocorrendo o fenômeno denominado eutrofização (BRAGA, 2005).

A importância da água não está relacionada apenas às suas funções na natureza, mas ao papel que exerce na saúde, economia e qualidade de vida humana. Nos últimos anos, a qualidade da água ao redor de nosso planeta tem se deteriorado de forma crescente, pois problemas relacionados com a poluição se intensificaram com o aumento significativo nos processos de urbanização e industrialização (GRASSI, 2001).

Há várias formas de poluição que afetam as reservas d'água, podendo estas ser classificadas em biológica, térmica, sedimentar e química. A poluição biológica é aquela que resulta da presença de microrganismos patogênicos, especialmente na água potável. A térmica ocorre frequentemente pelo descarte, nos corpos receptores, de grandes volumes de água aquecida usada no arrefecimento de uma série de processos industriais. A sedimentar resulta do acúmulo de partículas em suspensão, por exemplo, partículas de solo ou de produtos químicos insolúveis, orgânicos ou inorgânicos. A mais problemática é a contaminação química, causada pela presença de produtos químicos nocivos ou indesejáveis. A poluição química é um pouco diferente e um pouco mais simples que as outras formas de poluição. A poluição térmica tem pouco efeito sobre potabilidade da água. A sedimentar é normalmente muito visível e facilmente removível, até mesmo a poluição biológica parece em alguns casos menos perigosa do que a poluição química, uma vez que a maioria dos microrganismos pode ser destruída pela fervura da água que eles estejam infectando, ou pelo tratamento com substâncias químicas, como o hipoclorito de sódio e a cal viva. Já a poluição química não é assim tão simples de ser tratada (AZEVEDO, 1999).

A água é representada pelos rios, lagos, oceanos, lençóis subterrâneos e vapor de água, que constitui parte do ar atmosférico. Não há água pura na atmosfera, exceto aquela que existe na atmosfera em forma de vapor, que, no entanto, ao se precipitar em forma de chuva, carrega os gases atmosféricos.

É importante destacar que o Brasil possui $17 \%$ do total disponível no planeta, com 6,2 bilhões de $\mathrm{m}^{3}$ de água doce (ROCHA et al., 2004), sendo que cerca de $80 \%$ desta encontra-se na região amazônica, que recicla de 6 a 7 bilhões de toneladas de água doce por ano. No decorrer de toda a história da humanidade, o elemento água sempre esteve presente, não só como um bem necessário à sobrevivência do homem e demais seres vivos na Terra, mas ainda como fator determinante ao estabelecimento 
das civilizações às margens dos rios. Além de fornecer diversão e lazer, oferece empregos, alimentos e tantos outros benefícios. Com isso podemos perceber que a água é um dos recursos naturais mais intensamente utilizados. É fundamental para a existência e a manutenção da vida e, para isso, deve estar presente no ambiente em quantidade e qualidade apropriadas (SOUZA, 2008).

\section{Parâmetros da qualidade da água}

A qualidade de vida dos seres humanos está diretamente ligada à água, pois ela é utilizada para o funcionamento adequado do organismo, o preparo de alimentos, a higiene pessoal e utensílios. O uso de águas de lençóis e aquíferos apresentam algumas vantagens, dentre elas o alto grau de pureza, promovido pelo próprio solo. Ao contrário, as águas superficiais estão vulneráveis ao ambiente.

Os padrões de qualidade da água variam para cada tipo de uso preponderante. Considerando isto, o uso da água é definido pelos órgãos ambientais conforme o tipo e a classe a que ela pertence. O tipo e classe são obtidos por meio de parâmetros químicos, físicos e microbiológicos. A diferenciação entre águas minerais e potáveis é realizada pelo Código de águas Minerais, instituído pelo Decreto Lei № 7.841, de 1945 (VENDRAME, 2006).

A qualidade da água é aspecto indispensável, quando se trata dos seus principais usos, em especial, para fins como o abastecimento humano. Para cada finalidade existe um padrão de qualidade especificado pela legislação. Segundo a Portaria № 2.914, de 12 de dezembro de 2011, do Ministério da Saúde, é considerada água para consumo humano a água potável destinada à ingestão, preparação e produção de alimentos e à higiene pessoal, independentemente da sua origem, desde que atenda ao padrão de potabilidade estabelecido nesta Portaria e que não ofereça riscos à saúde;

Considerando que o padrão de potabilidade é o conjunto de valores permitidos como parâmetro da qualidade da água para consumo humano, neste estudo utilizaram-se os seguintes parâmetros físicos e químicos para avaliação da qualidade da água (RIGHES et al., 2009):

Cor: é uma característica física devido à existência de substâncias dissolvidas, ou em estado coloidal, na maioria dos casos de natureza orgânica. Pode originar-se de minerais ou vegetações naturais, ou ainda de despejos industriais que incluem minas, refinarias, explosivos, papelarias. A análise de cor pode ser definida de duas formas:

Cor Aparente: é a cor presente em uma amostra de água, devido à presença de substâncias dissolvidas e substâncias em suspensão;

Cor Verdadeira ou Real: é a cor presente em uma amostra de água, devido à presença de substâncias dissolvidas. A água pura é virtualmente ausente de cor.

Temperatura: tem importância por acelerar as reações químicas, reduzir a solubilidade dos gases e acentuar a sensação de sabor e odor. Exerce muita influência nas atividades biológicas e no crescimento. Normalmente o aumento da temperatura provoca um aumento da velocidade da reação.

Turbidez: representa a propriedade óptica de absorção e reflexão da lua. É devida à presença de partículas sólidas suspensas na água com tamanho que varia desde suspensões grosseiras aos coloides, dependendo do grau de turbulência. Entretanto não se pode relacionar unicamente a turbidez à sujeira da água, pois são muitos fatores que interferem na absorção e na reflexão da luz, como tamanho das partículas, sua forma geométrica dispersiva e sua coloração.

Dureza: a dureza na água para consumo humano está associada à presença de cátions metálicos, designadamente os íons cálcio $\left(\mathrm{Ca}^{2+}\right)$ e magnésio $\left(\mathrm{Mg}^{2+}\right)$. Uma água é considerada dura quando contém na sua composição valores significativos destes sais e macia quando os contém em pequenas quantidades. Em temperaturas elevadas, esses sais tendem a formar incrustações além de poder reagir com sabões e detergentes, reduzindo suas funções químicas.

Concentração residual de ferro: responsável por alterar a coloração da água, proporcionando um aspecto sujo. Em excesso os íons ferro podem reagir com o cloro residual livre, podendo atuar como protetor para microrganismos.

Sólidos totais dissolvidos: em saneamento, sólidos nas águas correspondem a toda matéria que permanece como resíduo, após evaporação, secagem ou calcinação da amostra a uma temperatura pré-estabelecida durante um tempo fixado. Em linhas gerais, as operações de secagem, calcinação e filtração são as que definem as diversas frações de sólidos presentes na água (sólidos totais, em suspensão, dissolvidos, fixos e voláteis). Os sólidos totais dissolvidos são constituídos, principalmente, por carbonatos, bicarbonatos, cloretos, sulfatos, fosfatos e, possivelmente, nitratos de cálcio, magnésio, potássio, pequenas quantidades de ferro, manganês e outras substâncias.

Determinação do valor de $p H$ : consiste na medida da concentração relativa dos íons de hidrogênio em uma solução. Esse valor indica acidez ou alcalinidade da solução. O valor do potencial hidrogeno iônico $(\mathrm{pH})$ é a medida da acidez ou alcalinidade relativa de uma determinada solução. Seu valor para a água pura a $25^{\circ} \mathrm{C}$ é igual a 7 e varia entre 0 e 7 , em meios ácidos, e entre 7 e 14 , em meios alcalinos. $\mathrm{O}$ pH é importante porque muitas reações químicas que ocorrem no meio ambiente são intensamente afetadas pelo seu valor (BRAGA et al., 2005).

\section{Metodologia}

Para o desenvolvimento deste estudo seguiu-se o planejamento descrito abaixo:

$1^{\circ}$ : Definição dos locais de coleta: realizou-se uma pesquisa bibliográfica avançada referente ao tema em questão. Em seguida, avaliou-se o mapeamento hidro geológico dos poços artesianos de alguns municípios do Rio Grande do Sul, para assim definir os possíveis pontos de amostras de água a serem coletados.

De acordo com este estudo e considerando o interesse da população, foram selecionados 33 pontos de coleta, 
divididos em 27 municípios do estado do Rio Grande do Sul. Dentre estes municípios optou-se por realizar análise em 2 localidades de Santa Maria (2 pontos no Bairro Centro e 1 ponto no Bairro Camobi), 1 em São Martinho da Serra, 3 em São João do Polêsine (Bairro Centro), 4 pontos na Região Noroeste do Rio Grande do Sul e 23 municípios da Região Central do Rio Grande do Sul, conforme descrito na Tabela 1 . Vale ressaltar que todas as amostras foram identificadas através de uma numeração, a fim de viabilizar a rastreabilidade. As coletas foram realizadas de acordo com a disponibilidade para realização das coletas das amostras.

2: Coleta das amostras: Antes da coleta das amostras, procedeu-se uma higienização da torneira, de onde a água é oriunda, com álcool etílico absoluto, e a primeira alíquota de água saída da torneira foi descartada. As amostras foram coletadas diretamente da torneira do poço artesiano utilizada pela população local, em frascos de polietileno, previamente esterilizados, armazenados e condicionados na geladeira do Laboratório de Análises Microbiológicas da Universidade Franciscana, até o momento das análises. Todas as amostras foram coletadas e analisadas no decorrer do ano de dois mil e dezessete. Todas as amostras foram coletadas em triplicata.

3: Análise das amostras: Para verificar a qualidade das amostras de água, oriundas destes locais de coleta, os procedimentos experimentais realizados foram (MACEDO, 2003):

Determinação da cor: Utilizou-se um equipamento denominado colorímetro, da Digimed, modelo DM-COR, onde a amostra de água foi inserida dentro de um frasco de vidro que vem acompanhado do colorímetro. Após, o mesmo foi inserido no equipamento para a leitura.

Determinação da temperatura: Utilizou-se, in loco, um termômetro digital. Para a leitura, o mesmo foi inserido dentro do frasco contendo a amostra.

Determinação da turbidez: Utilizou-se um turbidímetro da Digimed, modelo DM-TU. A amostra foi inserida dentro de um frasco de vidro que acompanha o turbidímetro, para a medição da turbidez.

Determinação dos sólidos totais dissolvidos: Aquecimento com chapa de aquecimento.

Determinação do valor de $\mathrm{pH}$ : Utilizou-se, in loco, um potenciômetro (pHmetro) portátil, da Denver Instrument, modelo UP-25. A amostra foi coletada dos pontos em estudo com um frasco de plástico previamente higienizado, dentro deste frasco insere-se o elétrodo acoplado ao equipamento para a leitura.

Determinação da dureza: Através de análise volumétrica por volumetria de complexação.

Determinação da concentração residual de ferro: Por meio da espectrofotometria UV/VIS.

Cabe salientar que todas as análises foram realizadas em triplicata.

4: Interpretação dos resultados: Após o desenvolvimento destas atividades avaliou-se os resultados obtidos, para assim, diagnosticar a qualidade da água e apresentar na comunidade em geral, através de trabalhos publicados e/ou participação em eventos, a fim de informar e conscientizar sobre a importância dessa questão.

\section{Resultados e discussão}

Vários fatores podem comprometer a qualidade da água subterrânea: o destino final do esgoto doméstico e industrial, a disposição inadequada de resíduos sólidos, os defensivos utilizados na agricultura, entre outros. Além dos microorganismos transmissores de doenças a água, está a sujeita e detritos, contaminações por ferro, por areia, lodo, sedimentos e muitos resíduos que podem prejudicar a saúde humana. Com isso, o consumo de água contaminada por agentes biológicos, químicos e físicos tem sido associado a diversos problemas de saúde.

Diante disto, a Tabela 1 descreve a localidade dos pontos de coleta, bem como os resultados obtidos nas análises das amostras de água de diferentes municípios do Estado do Rio Grande do Sul.

No município de São João do Polêsine foram realizadas coletas em três locais diferentes, em virtude do interesse e disponibilidade da população em avaliar a qualidade da água utilizada no seu consumo diário.

A Tabela 2 define os níveis de tolerância referente aos parâmetros analisados.

Conforme a Tabela 1 constatou-se que a maior parte dos resultados se enquadra dentro dos limites aceitáveis, de acordo com a norma de Qualidade da Água para Consumo Humano, Portarias № 518/2004 e № 2.914/2011, do Ministério da Saúde, através de análises físico-químicas, químicas e microbiológicas.

O pH determina o valor da concentração do íon de hidrogênio. Amostras de água com valores de $\mathrm{pH}$ abaixo de 7 são denominadas ácidas e tendem a ser corrosivas ou agressivas a tubulações, materiais à base de cimento e com valores de $\mathrm{pH}$ acima de 7 são denominadas alcalinas águas com pH alto, tendem a formar incrustações. Conforme a tabela 1 , os valores obtidos nas amostras analisadas, in loco, variaram entre 5,7 a 9,45. O pH pode afetar o metabolismo de várias espécies aquáticas. A Resolução CONANA № 357/2005 estabelece que para a proteção da vida aquática o pH deve estar entre 6 e 9. É importante destacar que os valores um pouco abaixo do aceitável não desqualificam a água quanto a sua potabilidade.

A cor da água é normalmente devido a decomposição orgânica de alguns ácidos (húmicos e tanino), os valores aceitáveis pela legislação vigente são de até 75 Pt-Co. Neste estudo obtiveram-se os resultados variando de 0,00 a 44,13 Pt-Co de cor, caracterizando assim, amostras de água adequadas para consumo humano. Segundo Scuracchio (2010) a cor aparente também tem importância estética e, quando alterada, provoca rejeição pelo consumidor.

A turbidez da água é devida à matéria em suspensão, alterando a penetração da luz através da difusão e absorção, dando à água uma aparência turva, esteticamente indesejável e potencialmente perigosa. Os resultados de turbidez apresentados, descreve valores variando entre 0,00 a 9,42 NTU, considerando que a legislação permite valores de até 5 NTU, corroborando com Campos, Farache Filho e Faria (2003) que obtiveram resultados inferiores a 5 NTU em todas as amostras analisadas. Segundo Silva e Araújo (2003), a turbidez, material em suspensão na água, 
Tabela 1 - Resultados obtidos nas análises das amostras de água de poços artesianos

\begin{tabular}{|c|c|c|c|c|c|c|c|}
\hline Localidade & $\mathrm{pH}$ & $\begin{array}{c}\text { Cor } \\
\text { (Pt-Co) }\end{array}$ & $\begin{array}{l}\text { Turbidez } \\
\text { (NTU) }\end{array}$ & $\begin{array}{l}\text { Dureza } \\
\text { (ppm) }\end{array}$ & $\begin{array}{c}\text { Temperatura } \\
\left({ }^{\circ} \mathrm{C}\right)\end{array}$ & $\begin{array}{l}\text { Sólidos totais } \\
\text { dissolvidos (g/L) }\end{array}$ & $\begin{array}{l}\text { Concentração de } \\
\text { ferro (ppm) }\end{array}$ \\
\hline São João do Polêsine & 8,82 & 2,2 & 0,3 & 12 & 20,7 & 1,374 & $<\mathrm{LOD}^{*}$ \\
\hline Faxinal do Soturno & 9,45 & 3,57 & 0,93 & 19,33 & 22,8 & 1,406 & $<\mathrm{LOD}^{*}$ \\
\hline Silveira Martins & 6,16 & 43,67 & 9,42 & 26 & 18,4 & 0,1166 & $<\mathrm{LOD}^{*}$ \\
\hline Ivorá & 7,59 & 2,9 & 0,3 & 79,33 & 22 & 0,20933 & $<\mathrm{LOD}^{*}$ \\
\hline Nova Palma & 8,97 & 4,03 & 0,8 & 12,67 & 21,3 & 0,1686 & $<\mathrm{LOD}^{*}$ \\
\hline Dona Francisca & 7,37 & 2,33 & 0,19 & 160,6 & 22,4 & 0,1973 & $<\mathrm{LOD}^{*}$ \\
\hline Agudo & 7,36 & 7,67 & 1,98 & 72 & 21,4 & 0,1 & $<\mathrm{LOD}^{*}$ \\
\hline Itaara & 7,00 & 29,3 & 1,25 & 34,66 & 16,4 & 0,0546 & $<\mathrm{LOD}^{*}$ \\
\hline Toropi & 6,00 & 19,36 & 4,4 & 42 & 20 & 0,1606 & $<\mathrm{LOD}^{*}$ \\
\hline Santa Maria & 7,00 & 8,63 & 0,36 & 24,6 & 19 & 0,053 & $<$ LOD* $^{*}$ \\
\hline São Francisco de Assis & 7,68 & 15,03 & 4,98 & 38,66 & 17,6 & 0,07 & $<\mathrm{LOD}^{*}$ \\
\hline São Vicente do Sul & 7,74 & 4,67 & 0,43 & 144 & 19,5 & 0,19 & $<\mathrm{LOD}^{*}$ \\
\hline São Pedro do Sul & 6,03 & 5,47 & 0,7 & 25,33 & 20,5 & 0,0746 & $<\mathrm{LOD}^{*}$ \\
\hline São Sepé & 5,8 & 44,13 & 13,36 & 45,33 & 19,8 & 0,22 & $<\mathrm{LOD}^{*}$ \\
\hline Formigueiro & 6,84 & 30,43 & 4,27 & 121,33 & 16,5 & 0,3467 & $<\mathrm{LOD}^{*}$ \\
\hline São Luiz Gonzaga & 5,70 & 0 & 0 & 13,3 & 21,3 & 0 & $<\mathrm{LOD}^{*}$ \\
\hline Paraíso do Sul & 7,30 & 8,3 & 0,28 & 36 & 19,9 & 0,1934 & $<\mathrm{LOD}^{*}$ \\
\hline Novos Cabrais & 8,67 & 9,03 & 0,39 & 20 & 19,7 & 0,952 & $<\mathrm{LOD}^{*}$ \\
\hline Restinga Seca & 6,6 & 23 & 4,53 & 30 & 18,9 & 0,22 & $<\mathrm{LOD}^{*}$ \\
\hline Santa Maria (Camobi) & 6,81 & 22,37 & 7,78 & 49,33 & 18,2 & 0,0646 & $<\mathrm{LOD}^{*}$ \\
\hline São Martinho de Serra & 6,00 & 10,6 & 0,67 & 48,66 & 20 & 0,154 & $<\mathrm{LOD}^{*}$ \\
\hline Cruz Alta & 6,82 & 8,2 & 0,56 & 38 & 23 & 0,1413 & $<\mathrm{LOD}^{*}$ \\
\hline ljuí & 6,70 & 7,7 & 0,32 & 92 & 20,3 & 0,2273 & $<\mathrm{LOD}^{*}$ \\
\hline Augusto Pestana & 7,55 & 10,1 & 0,34 & 96,66 & 20,9 & 0,2646 & $<\mathrm{LOD}^{*}$ \\
\hline Tupanciretã & 7,80 & 7,1 & 0,31 & 90 & 23,2 & 0,208 & $<\mathrm{LOD}^{*}$ \\
\hline Júlio de Castilhos & 7,20 & 7,5 & 0,28 & 34 & 22,6 & 0,1653 & $<\mathrm{LOD}^{*}$ \\
\hline Santa Maria & 8,15 & 8,03 & 0,37 & 52 & 21,5 & 0,274 & $<\mathrm{LOD}^{*}$ \\
\hline Candelária & 6,80 & 32,1 & 6,22 & 56,6 & 21,2 & 0,218 & $<\mathrm{LOD}^{*}$ \\
\hline Vera Cruz & 6,70 & 12,57 & 1,12 & 94,6 & 21 & 0,216 & $<\mathrm{LOD}^{*}$ \\
\hline Sinimbú & 5,70 & 16,4 & 2,95 & 23,3 & 20,5 & 0,1253 & $<\mathrm{LOD}^{*}$ \\
\hline Herveiras & 6,10 & 19,83 & 4,41 & 24,66 & 20,6 & 0,046 & $<\mathrm{LOD}^{*}$ \\
\hline São João do Polêsine & 8,00 & 10,53 & 0,27 & 48,66 & 21 & 0,766 & $<\mathrm{LOD}^{*}$ \\
\hline São João do Polêsine & 7,6 & 14,57 & 1,62 & 120,6 & 19,5 & 0,6813 & $<\mathrm{LOD}^{*}$ \\
\hline
\end{tabular}

*LOD (limite de detecção): 4 × 10-4 ppm

Temp.: temperatura

Pt-Co: platina de cobalto

pode se fixar aos patógenos existentes, protegendo-os e até dificultando a ação do cloro sobre os mesmos. Siqueira et al. (2012), ao avaliarem a qualidade da água do rio Parauapebas, encontraram valores de turbidez dentro dos padrões da legislação, que oscilou em consequência do material em suspensão devido à entrada de materiais carreados para o rio.

A concentração de cátions metálicos em solução, principalmente cálcio e magnésio, causa sabor desagradável, podendo ter efeito laxativo. Considerando os resultados obtidos na análise da dureza, observa-se que variam de 12 a $160,6 \mathrm{mg} \mathrm{L}^{-1}$ a concentração de carbonato de cálcio para as amostras em estudo, sendo que o valor aceitável é de até $500 \mathrm{mg} \mathrm{L}^{-1}$. Porém, em alguns casos, em temperaturas elevadas, esses minerais tendem a formar incrustações além de poder reagir com sabões e detergentes, reduzindo suas funções químicas.

A temperatura das amostras variou entre 16,4 a 23,2 ${ }^{\circ} \mathrm{C}$, no momento de coleta, sendo que os valores aceitáveis são de até $25{ }^{\circ} \mathrm{C}$. É importante destacar que a tempera- 
Tabela 2 - Resultados obtidos nas análises das amostras de água de poços artesianos

\begin{tabular}{|c|c|c|c|c|c|c|c|}
\hline \multicolumn{8}{|c|}{ Níveis de Tolerância } \\
\hline & $\mathrm{pH}$ & Cor (Pt-Co) & $\begin{array}{c}\text { Turbidez } \\
\text { (NTU) }\end{array}$ & $\begin{array}{c}\text { Dureza } \\
\text { (ppm) }\end{array}$ & $\begin{array}{c}\text { Temperatura } \\
\left({ }^{\circ} \mathrm{C}\right)\end{array}$ & $\begin{array}{c}\text { Sólidos totais } \\
\text { dissolvidos (g/L) }\end{array}$ & $\begin{array}{l}\text { Concentração de } \\
\text { ferro (ppm) }\end{array}$ \\
\hline Classe 1(a) & $6,0<\mathrm{pH}<9,0$ & i & $<40$ & -- & -- & $<500$ & -- \\
\hline Classe 2(a) & $6,0<p H<9,0$ & $<75$ & $<100$ & -- & -- & $<500$ & -- \\
\hline Classe 3(a) & $6,0<\mathrm{pH}<9,0$ & $<75$ & $<100$ & -- & -- & $<500$ & -- \\
\hline ANVISA(b) & $6,0<\mathrm{pH}<9,0$ & $<15$ & $<5,0$ & $<500$ & $5<\mathrm{T}\left({ }^{\circ} \mathrm{C}\right)<30$ & $<1000$ & -- \\
\hline
\end{tabular}

(a) CONAMA No 357 (BRASIL, 2005);

(b) ANVISA, Portaria No 2.914 (BRASIL, 2011);

i "cor verdadeira: nível de cor natural do corpo de água em mg Pt L-1" (BRASIL, 2005);

Potável: $[\mathrm{Fe}]<0,3 \mathrm{mg} \mathrm{L}^{-1}$ (BRASIL, 2011). Classe 1: $[\mathrm{Fe}]<0,3 \mathrm{mg} \mathrm{L}^{-1}$. Classe $3[\mathrm{Fe}]<5,0 \mathrm{mg} \mathrm{L}^{-1}$ (BRASIL, 2005).

tura influência nas atividades biológicas, além de alterar algumas características químicas, como por exemplo, o nível de oxigênio dissolvido, visto que a água em temperatura mais alta contém menos oxigênio dissolvido do que a água em temperatura mais baixa.

Todas as impurezas, com exceção dos gases dissolvidos, são consideradas como sólidos totais suspensos em água. Altas concentrações de sólidos reduzem a passagem de luz solar. Nas amostras analisadas os valores de sólidos totais dissolvidos variaram entre 0 a $1,406 \mathrm{~g} \mathrm{~L}^{-1}$, sendo que os valores aceitáveis são de até $0,5 \mathrm{~g} \mathrm{~L}^{-1}$.

O ferro é o principal mineral, responsável por alterar a coloração da água, proporcionando um aspecto sujo. Conferem sabor, odor, coloração e turbidez à água, além de depositarem-se nas tubulações, causando corrosão e incrustações. Na determinação do teor de ferro, não foram detectados resíduos de ferro nas amostras analisadas.

\section{Considerações finais}

Os mananciais subterrâneos são recursos naturais utilizados tradicionalmente para abastecer grande parte da população brasileira em áreas rurais e urbanas, cumprem função importante e, em inúmeros casos, é vital para o fornecimento de água potável. A água é um bem de primeira necessidade, constituindo-se um recurso de uso comum (SOTO et al., 2006).

As águas subterrâneas cumprem função importante e, em inúmeros casos, é vital para o fornecimento de água potável. Por isso, recomenda-se a sua proteção, com eliminação das causas de possíveis contaminações, bem como o uso de filtração, antes da desinfecção, para reduzir, a um nível significante, o risco de transmissão de parasitos pela água (Abramovich et al., 1998).

Neste estudo foram avaliadas a qualidade da água de poços artesianos com diferentes profundidades, entre 70 e 80 metros, cobertura vegetal, de uso agrícola e urbano, localizados em alguns municípios do Estado do Rio Grande do Sul. As variações dos parâmetros analisados auxiliaram no entendimento das propriedades que caracterizam a qualidade da água.
De acordo com o objetivo principal do trabalho em questão, de diagnosticar a qualidade da água oriunda de poços artesianos do Rio Grande do Sul, quanto ao valor de $\mathrm{pH}$, cor, turbidez, dureza, temperatura, sólidos totais dissolvidos e concentração residual de ferro, a avaliação dos resultados obtidos foi baseada nos padrões de potabilidade estabelecidos na na Portaria № 2.914 , de 12 de dezembro de 2011, do Ministério da Saúde. Com a realização das análises e interpretação dos resultados, compararam-se os valores obtidos com valores aceitos legalmente. Assim, averiguou-se que a maior parte dos resultados obtidos nos processos experimentais está de acordo com os parâmetros de potabilidade. Portanto o consumo destas amostras analisadas é indicado para a população.

O consumo humano de água que não atenda aos padrões de potabilidade recomendados precisa ser evitado, principalmente através do acesso à informação e da promoção de políticas públicas que garantam o acesso generalizado à água adequada ao consumo humano, visto que constitui-se em uma das ações de saúde pública de maior impacto na prevenção de doenças e dos índices de mortalidade.

Por fim, pretende-se apresentar as informações obtidas referente as propriedades de qualidade da água de poços artesianos, para a comunidade.

\section{Agradecimentos}

Agradecimentos aos revisores e a Universidade Franciscana de Santa Maria (UFN).

\section{Referências}

ABRAMOVICH B., CARRERA E., LURÁ M.C. \& HAYE M.A. 1998. Cryptosporidium y agua: estudio de una asociación riesgosa. Ingeniería Sanitaria y Ambiental 36:30-34. 
AZEVEDO, E. B. Poluição vs. Tratamento de Água: duas faces da mesma moeda. Química e Sociedade, São Paulo, no 10, nov. 1999.

BRAGA, B. Introdução à Engenharia Ambiental. 2 ed. São Paulo: Pearson Prentice Hall, 2005.

BRASIL. Ministério da Saúde. Portaria № 518, de 25 de março de 2004. Estabelece os procedimentos e responsabilidades relativos ao controle e vigilância da qualidade da água para consumo humano e seu padrão de potabilidade, e dá outras providências.

BRASIL. Resolução CONAMA № 357, de 17 de março de 2005. Dispõe sobre a classificação dos corpos de água e diretrizes ambientais para o seu enquadramento, bem como estabelece as condições e padrões de lançamento de efluentes, e dá outras providências. Diário Oficial da República federativa do Brasil, Brasília, Seção 1, p. 58-63. 2005.

BRASIL. Ministério da Saúde. Portaria № 2.914, de 12 de dezembro de 2011. Dispõe sobre os procedimentos de controle e de vigilância da qualidade da água para consumo humano e seu padrão de potabilidade. Diário Oficial da União 2011; 14 dez.

CAMPOS, J. A. D. B.; FARACHE FILHO, A.; FARIA, J. B. Uso de reservatórios domiciliares e conhecimento da população. Rev. Alim. Nutr., v. 14, n. 2, p. 171- 175, 2003.

Conselho Nacional do Meio Ambiente - CONAMA. Resoluções do Conselho Nacional do Meio Ambiente. Ministérios do Meio Ambiente. Brasília/DF, 2006.

GRASSI, M. T. As águas do planeta Terra. Cadernos Temáticos de Química Nova na Escola. São Paulo, ed. especial, maio, 2001.

HIRATA, R. O que é um poço artesiano. Revista Super Interessante, São Paulo, set. 2002.

MACÊDO, J. A. B. de. Métodos Laboratoriais de Análises Físico-Químicas e Microbiológicas. 2 ed. Belo Horizonte - MG: MACÊDO, 2003.

Righes, A. A.; BURIOL, G. A.; BOER, N. Água e Educação - Princípios e estratégias de uso e conservação. Santa Maria: Paula Schoenfeldt Patta, 2009.

ROCHA, T. C.; ROSA, A. H.; CARDOSO, A. A. Introdução à química ambiental. Porto Alegre: Bookmam, 2004.

SCURACCHIO, P. A. Qualidade da água utilizada em escolas do município de São Carlos-SP. Dissertação de Mestrado. Universidade Estadual Paulista, 2010.
SILVA R. C. A.; ARAÚJO T. M. Qualidade da água do manancial subterrâneo em áreas urbanas de Feira de Santana (BA). Ciência e Saúde Coletiva, 8 (4): 1019:1028, 2003.

SIQUEIRA, G.W.; APRILE, F.; MIGUÉIS, A.M. Diagnóstico da qualidade da água do rio Parauapebas (Pará - Brasil). Acta Amazônica. v. 42, n. 3, p. 413 - 422, 2012.

SOTO, F. R. M.; FONSECA, Y. S. K; RISSSETO, M.; AZEVEDO, S. S. de. ARINO, M. L. B; RIBAS, M. A.; MOURA, C. R.V.; MACHETTE, D. S. Monitoramento da qualidade da água de poços rasos de escolas públicas da zona rural do Município de Ibiúna/SP: parâmetros microbiológicos, físico-químicos e fatores de risco ambiental. Ver. Inst. Adolfo Lutz. v. 65, n. 2, 2006, p. 106-111.

SOUZA, L. C. de. Águas e sua proteção. $1^{\circ}$ ed. (ano 2004), $4^{\circ}$ tir. Curitiba: JURUÁ, 2008.

VENDRAME, A. C. Perícia Ambiental - Uma abordagem Multidisciplinar. São Paulo: IOB Thomson, 2006.

Contribuição dos autores

Sandra Cadore Peixoto

Contribuições substanciais para a concepção do trabalho; aquisição; análise e interpretação de dados; redigiram o trabalho e realizaram uma revisão substancial.

Carolina Denardi Merlugo

Contribuições substanciais para a concepção do trabalho; aquisição; análise e interpretação de dados; redigiram o trabalho e realizaram uma revisão substancial.

Anderson Maciel

Análise e interpretação de dados; redigiram o trabalho e realizaram uma revisão substancial.

Tiago Barboza Solner

Anălise e interpretação de dados; redigiram o trabalho e realizaram uma revisão substancial. 